\title{
Short-term Tagging Mortality of Laboratory Held Juvenile Atlantic Herring (Clupea $h$. harengus)
}

\author{
Wayne T. Stobo and G. Mark Fowler \\ Marine Fish Division, Department of Fisheries and Oceans \\ Bedford Institute of Oceanography, P. O. Box 1006, Dartmouth, Nova Scotia, Canada B2Y 4A2 \\ and \\ Alan F. Sinclair \\ Fisheries Research Division, Department of Fisheries and Oceans \\ Maurice Lamontagne Institute, C. P. 1000, Mont-Joli, Quebec, Canada G5H $3 Z 4$
}

\begin{abstract}
Mortality of weir-caught herring $11-23 \mathrm{~cm}$ in length and tagged with two sizes of plastic anchor tags was monitored for 21 days in laboratory tanks. Although the presence of tags caused a significant increase in mortality, significant differences were not found between the tag sizes examined. The most important factor determining mortality was fish length, with experimental variability being the next most important factor. Mortality continued throughout the experiment, thus lactic acid accumulation due to stress at the time of capture did not adequately explain the cause of mortality. The experiments suggested that survivorship in the field would be improved by tagging herring no less than $17 \mathrm{~cm}$ in length and by minimizing stress and injury during capture and handling.
\end{abstract}

\section{Introduction}

Large-scale external tagging of Atlantic herring (Clupea $h$. harengus) in NAFO Subarea 4 was initiated in 1973 to ascertain movements and discreteness of stocks to aid in formulating fishery management policy. By 1976 it was apparent that tag recoveries, like those of previous herring tagging programs in the Northwest Atlantic (Winters and Beckett, 1978; McKenzie and Tibbo, 1961; McKenzie and Skud, 1958), were considerably less than those obtained from markrecapture studies with groundfish species (e.g. McCracken, 1957; Jensen, 1963; Kohler, 1964). Several reasons for such return rates have been postulated (Parrish and McPherson, 1963; Stobo, MS 1976), including the possibility that herring were simply too delicate to withstand the tagging operation.

Hay (1981) examined tagging mortalities of Pacific herring (Clupea harengus pallasi) in the laboratory, but used fish that had been acclimated to captivity for 4-16 months prior to tagging. Consequently, the physiological state of those fish may have been quite different from fish in the wild. Nakashima and Winters (1984) assessed various aspects of capture stress and tag type in field studies by comparing observed return rates with those expected using mortality estimates obtained from cohort analysis. Jonsson and Scabell (MS 1984) attempted to better approximate field conditions by holding Ruegen spring herring in net cages in the wild; their experiment was terminated by inclement weather on the 11 th day.

In 1977, we conducted a series of laboratory experiments to examine short-term post-tagging mortality in juvenile Atlantic herring. None of the previous work had considered some of the key parameters in our study, most notably fish size. We hope this paper increases the present understanding of tagginginduced herring mortality.

\section{Methods}

Herring for the experiments were collected from weirs in the vicinity of Passamaquoddy Bay (Fig. 1) in the southwestern part of NAFO Subarea 4 . The fish were seined and removed by dip nets fitted with waterfilled buckets, then transferred to $0.9 \mathrm{~m}$ diameter $\times 0.6$ $m$ deep fibreglass tanks on board the M/V Pandalus for transportation to the Biological Station in St. Andrews, New Brunswick. The shipboard tanks containing the fish were disembarked to indoor holding facilities; the fish were then tagged and transferred to the experimental tanks. Fish that exhibited noticeable injury (e.g. scale loss) were not used in the experiments. Running seawater was supplied throughout the capture, transfer and tagging operations. To the extent possible, we duplicated normal field capture and tagging conditions. 


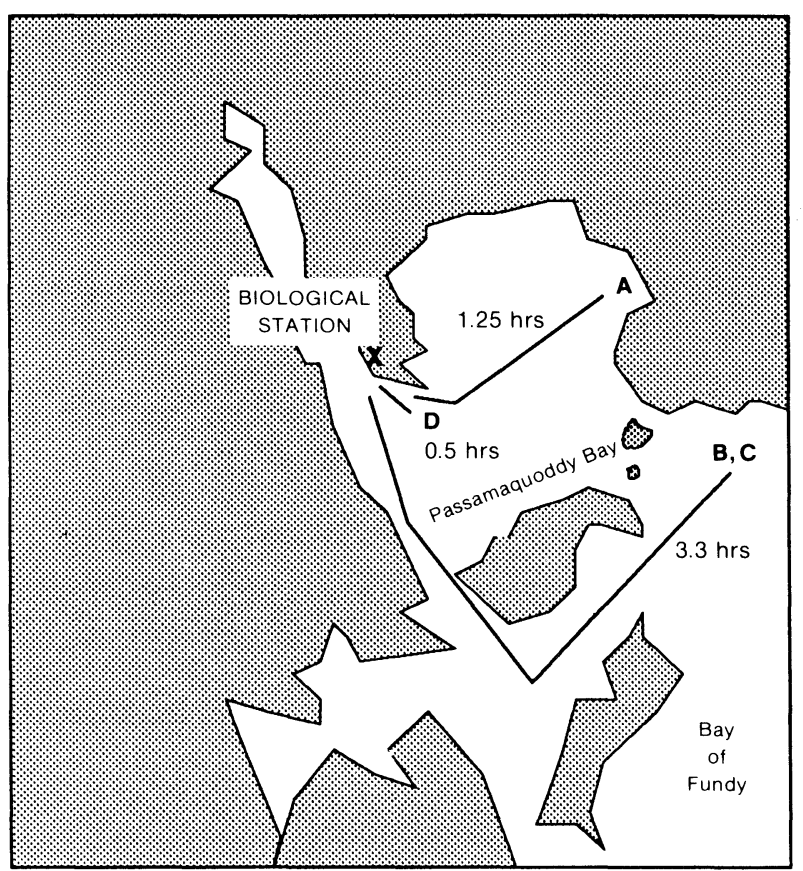

Fig. 1. Map of Passamaquoddy Bay area showing capture locations and transit times to the laboratory for the four experiments $A$, $\mathrm{B}, \mathrm{C}$ and $\mathrm{D}$.

The tags used were Floy plastic anchor tags (Floy Tag Co., Seattle, Washington, USA). Each had a Tshaped anchor and an external coloured vinyl tube with a unique number. Two different sizes of tags with different lengths of vinyl tubing were applied, the Fine Fabric type with $40 \mathrm{~mm}$ tubing and the FD-68B type with 62 $\mathrm{mm}$ tubing. The tag anchor was injected into the fish by a gun equipped with a slotted, hollow needle. Tags were inserted diagonally between the dorsal interneural bones of the fish, as described in Stobo (MS 1976). The same equipment and procedures were used for large-scale field tagging studies on herring (Stobo, MS 1983).

In each of four experiments (denoted as A, B, C and $D$ ) the treatments were such that roughly equal numbers of fish were tagged with either small anchor tags or large anchor tags, or were mock handled as if to be tagged. In the mock handled control group, neither the tagging needle nor tag were inserted into the fish musculature. The fish were then placed in $1.8 \mathrm{~m}$ diameter $\times 0.9 \mathrm{~m}$ deep insulted fibreglass tanks with cooling units, circulating pumps, constant aeration and running seawater. The water temperature in the tanks was controlled to approximate the ambient field conditions $\left(11^{\circ}\right.$ to $\left.14^{\circ} \mathrm{C}\right)$ at the time of capture.

Random length frequency samples and stratified samples for length-weight relationships were taken from each capture site. At the completion of each experiment, a length frequency of the survivors was taken and the length-weight relationship of these fish was determined. During the experiments, a daily record was kept of the number of dead fish and their lengths, and of the general conditions of survivors. Length frequencies of the laboratory fish by experiment and treatment, comprising both survivors and dead fish, are presented in Fig. 2.

Any laboratory experiment misrepresents the natural environment to some extent (e.g. restricted environment, isolation from natural predators and food sources, and other environmental stresses), so results cannot be taken as exact duplication of field tagging conditions. Since the impact of such differences in conditions could increase with time, it was decided to restrict the experiments to consideration of short-term (three weeks) effects. Hence, this investigation does not consider longer-term aspects of mortality due to carrying an external tag (e.g. impaired swimming ability, greater visibility to predators) or assumed mortality due to tag loss.

It had originally been intended that the investigation would comprise four experiments of three treatments each (control, small tags and large tags), with two replicates of each treatment within each experiment. Availability of fish, however, resulted in some variation in the sample sizes between experiments, treatments and replicates. Early in the analysis it was realized that tank density as a factor affecting mortality should also be examined. Although the number of fish which died in each replicate was documented, the data record did not indicate the final number of fish used per replicate. The actual numbers of fish per teatment, however, were recorded and the intended number of animals per replicate were known from the original experimental design. These two sources were used to estimate sample size per replicate within treatment, then tested for density effects using the estimated replicate mortalities (proportion of animals in each replicate which died). Table 1 outlines the sample sizes by experiment and treatment, and the estimated replicate sizes.

For the purpose of contrasting results between experimental groups of different sizes, mortalities are expressed as proportions (i.e. deaths/initial numbers) of sample (treatment or replicate) size. A symmetric residual distribution for analysis of variance was obtained by applying an arcsine transformation (Ott, 1988) to the proportionate mortalities. This was the only part of the analysis in, which the mortality estimates by replicate were used. All statistical tests were conducted using the SPSS $\times$ system. The SPSS $\times$ procedure 'ANOVA' using the regression approach was applied to the replicates (combined across treatments), to test for tank density effects (within experiment) on mortality. The SPSS $\times$ procedure 'MANOVA' was used 

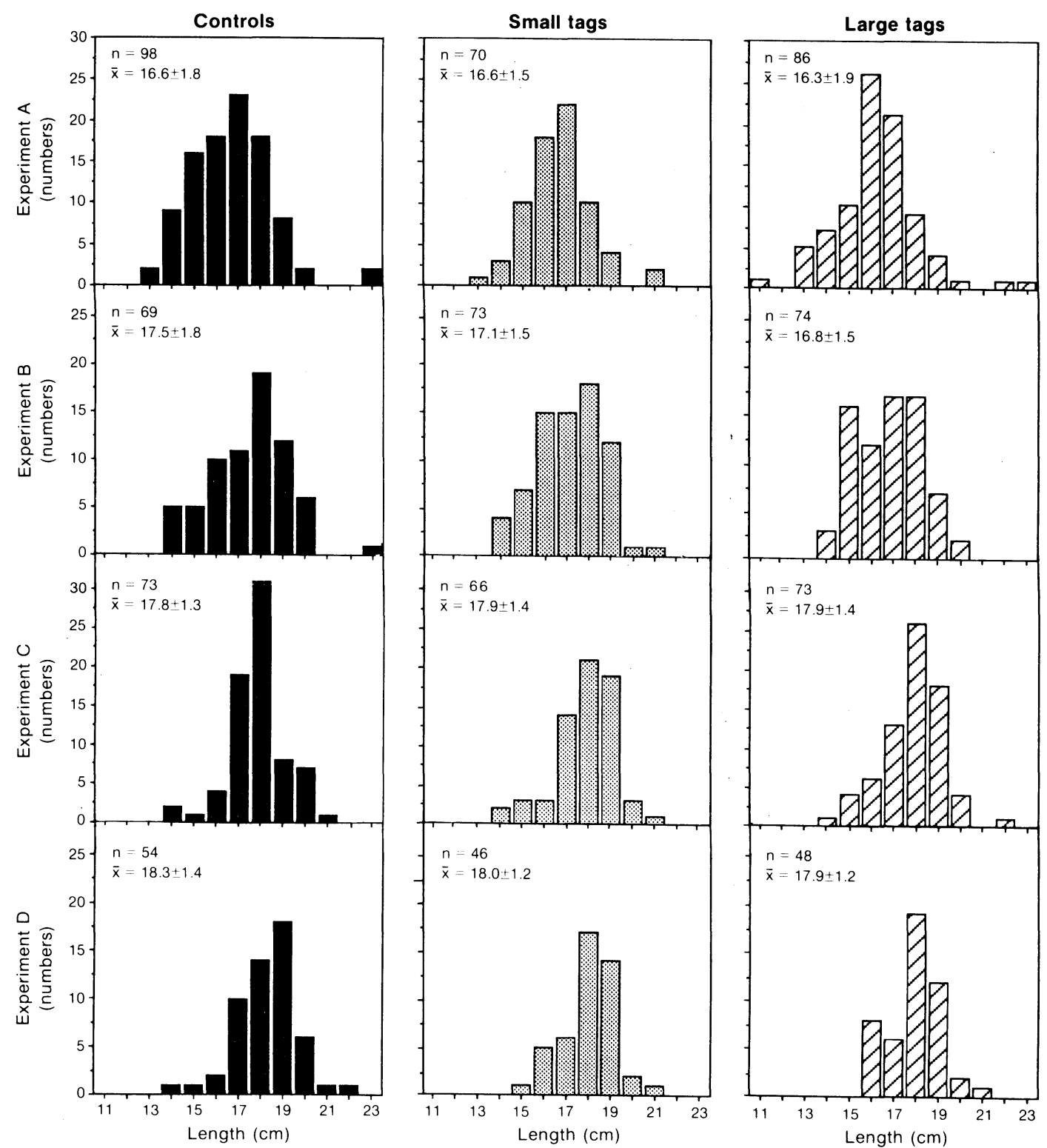

Fig. 2. Length composition of herring used in the study, by experiment and treatment.

to conduct analysis of covariance (length as the covariate) to the treatments (combined across replicates) to test for treatment, fish length and experiment effects. Insignificant interaction terms (length-treatment, experiment-treatment) were removed from the model. Significant interaction between length and experiment prevented use of a standard main effects model. Loglinear analysis of the data (in binary form) was applied to resolve the length-experiment interaction. Treatment, experiment and the length-experiment interaction term were used as factors, with length as a covariate. The deviation parameter estimates were then contrasted to test for differences between treatments. Significance levels of $P \leqslant 0.05$ were used throughout.

\section{Results}

Regardless of treatment, the survivors weighed less than the random samples taken at commencement of the experiments, suggesting weight loss over the duration of the experiment (Fig. 3). The extent of weight loss was not related to initial size, and occurred even though food (frozen brine shrimp) was provided daily.

Although care had been taken during tagging to exclude fish with noticeable injury, it was observed that those fish dying in the first 3-4 days were characterized by scale loss. Observed cumulative mortalities (Fig. 4) 
TABLE 1. Treatment and replicate sample summaries of the four experiments.

\begin{tabular}{|c|c|c|c|c|c|}
\hline Experiment & Treatment & $\begin{array}{l}\text { Treatment } \\
\text { sample } \\
\text { size }\end{array}$ & $\begin{array}{c}\text { Replicate } \\
\text { (tank) }\end{array}$ & $\begin{array}{l}\text { Approximate } \\
\text { replicate } \\
\text { sample } \\
\text { size }\end{array}$ & $\begin{array}{c}\text { Density } \\
\text { factor } \\
\text { class }\end{array}$ \\
\hline \multirow[t]{6}{*}{ A } & small tag & 70 & 1 & 35 & 1 \\
\hline & & & 2 & 35 & 1 \\
\hline & large tag & 86 & 1 & 43 & 1 \\
\hline & & & 2 & 43 & 1 \\
\hline & control & 98 & 1 & 49 & 1 \\
\hline & & & 2 & 49 & 1 \\
\hline \multirow[t]{6}{*}{ B } & small tag & 73 & 3 & 48 & 1 \\
\hline & & & 4 & 25 & 2 \\
\hline & large tag & 74 & 3 & 49 & 1 \\
\hline & & & 4 & 25 & 2 \\
\hline & control & 69 & 3 & 46 & 1 \\
\hline & & & 4 & 23 & 2 \\
\hline \multirow[t]{6}{*}{ C } & small tag & 66 & 5 & 44 & 1 \\
\hline & & & 6 & 22 & 2 \\
\hline & large tag & 73 & 5 & 48 & 1 \\
\hline & & & 6 & 25 & 2 \\
\hline & control & 73 & 5 & 48 & 1 \\
\hline & & & 6 & 25 & 2 \\
\hline \multirow[t]{6}{*}{$D$} & small tag & 46 & 7 & 23 & 2 \\
\hline & & & 8 & 23 & 2 \\
\hline & large tag & 48 & 7 & 24 & 2 \\
\hline & & & 8 & 24 & 2 \\
\hline & control & 54 & 7 & 27 & 2 \\
\hline & & & 8 & 27 & 2 \\
\hline
\end{tabular}

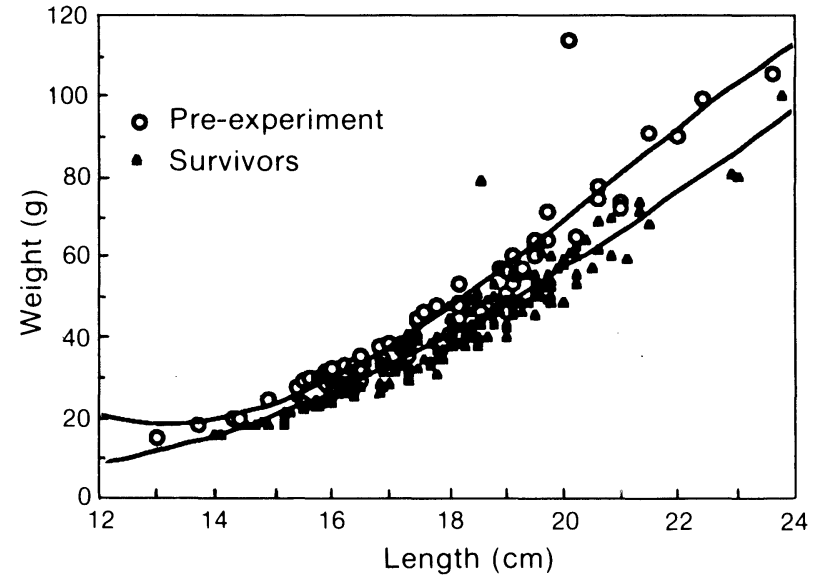

Fig. 3. Fitted length-weight relationships of pre-experiment random samples and post-experiment survivors. All experiments and treatments are combined.

increased through the 21 days of the study for all three treatment groups. Mortality was higher during the first 2 weeks than in the last week of each experiment. In the control group, the change in cumulative mortality was small and the increase was essentially linear. In the tagged groups, the change in mortality rate at the end of the second week was more pronounced. Within each experiment, a similar order of mortality was observed (Table 2) even though substantial differences in overall

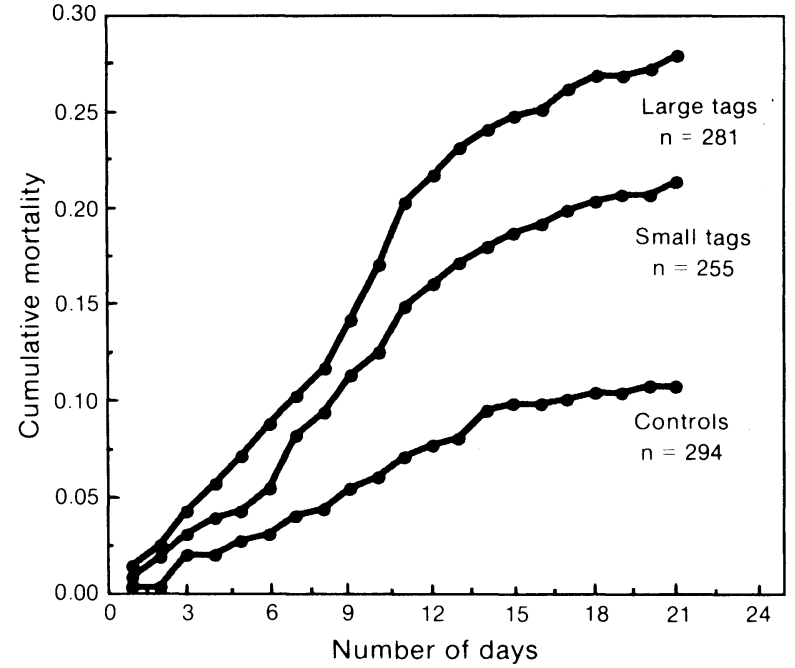

Fig. 4. Cumulative mortality by treatment during the three week period, combined across experiments.

mortality occurred between experiments. Mortality was lower in the control group than for groups bearing tags, and lower mortality was observed for fish with the small tag than the large tag. Even when adjusted for mortality in the control group, substantial between experiment variation persisted in the tagged groups, and the highest observed mortalities persisted in the experiments 
which exhibited the highest control group mortalities. In all experiments greater mortality was observed among small fish. Combining data across experiments and treatments (Fig. 5) indicated a high mortality in fish under $17 \mathrm{~cm}$ in length, decreasing dramatically to very low mortalities at greater lengths.

The analysis of variance on replicates with experiment and tank density as main effects indicated that experiment was significant $(F=18.86, P=0.019)$, and accounted for $90.3 \%$ out of a total of $95.2 \%$ explained variance, while density was not significant $(F=1.53, P=$ $0.537)$. The analysis of covariance across replicates (Table 3 ) attributed $28.3 \%$ of the total variance to length, $12.4 \%$ to experiment, $1.1 \%$ to treatment, and $9.3 \%$ to interaction between length and experiment. Both fish length and experiment were significant sources of variation, as was the interaction between them, but treatment was not $(P=0.365)$. The adjusted means (i.e. adjusted for length) predicted by the analysis of covariance of the arcsine transformed mortalities for levels of a factor (Table 4) indicated that mortality was lowest in experiment $A$ and increased in the order $C, D$, and then $B$.

Log-linear analysis of mortalities explained only $16 \%$ of the variation, but with a likelihood ratio of 0.74 ( $P$ $=0.864)$. The length-experiment interaction effect was successfully corrected for, permitting treatments to be compared. Contrasts between treatments (Table 5) demonstrated a significant difference in mortality between controls and large tags $(P<0.001)$, but not between controls and small tags, or between small and large tags. The negative coefficients associated with the contrasts, however, could be indicative of a trend in increasing mortality from control to small tag to large tag.

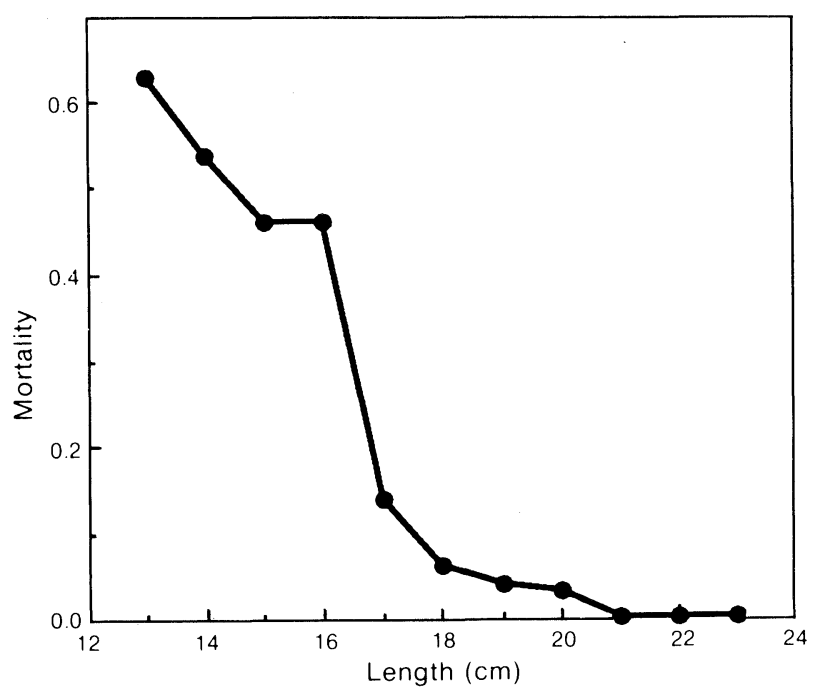

Fig. 5. Mortality at length, combined across experiments and treatments. A single $11 \mathrm{~cm}$ fish (which survived) was excluded as an outlier.
TABLE 2. Proportionate herring mortalities by experiment and treatment. Mortalities for the within experiment tagged groups, corrected for control mortalities, are given in brackets.

\begin{tabular}{ccccccc}
\hline & \multicolumn{5}{c}{ Treatment } \\
\cline { 2 - 7 } Experiment & Controls & \multicolumn{2}{c}{ Small tag } & \multicolumn{2}{c}{ Large tag } \\
\hline A & 0.04 & 0.09 & $(0.05)$ & 0.12 & $(0.08)$ \\
B & 0.28 & 0.47 & $(0.19)$ & 0.50 & $(0.22)$ \\
C & 0.04 & 0.11 & $(0.07)$ & 0.15 & $(0.11)$ \\
D & 0.11 & 0.17 & $(0.06)$ & 0.38 & $(0.27)$ \\
\hline
\end{tabular}

TABLE 3. Analysis of covariance of arcsine-transformed proportionate herring mortalities. Length is a covariate. The percentage of total variation explained by each component sum of square is given in brackets.

\begin{tabular}{lrrrrr}
\hline \multicolumn{1}{c}{ Source of variation } & \multicolumn{2}{c}{ Sum of squares } & d.f. & \multicolumn{1}{c}{$F$} & P value \\
\hline Fish length (Len) & 14510.5 & $(28.3)$ & 1 & 50.52 & 0.000 \\
Treatment & 585.8 & $(1.1)$ & 2 & 1.02 & 0.365 \\
Experiment (Exp) & 6359.5 & $(12.4)$ & 3 & 7.38 & 0.000 \\
Len-Exp interaction & 4744.5 & $(9.3)$ & 3 & 5.51 & 0.002 \\
\hline Total explained variation & 26200.3 & $(51.2)$ & 9 & & \\
Total variation & 51188.9 & & 96 & & \\
\hline
\end{tabular}

TABLE 4. Adjusted means from the analysis of covariance of arcsinetransformed proportionate herring mortalities. The 'number of cases' is the result of aggregating the data into the various combinations for experiment, treatment and length.

\begin{tabular}{lccc}
\hline Factor & Category & $\begin{array}{c}\text { No. of } \\
\text { cases }\end{array}$ & $\begin{array}{c}\text { Adjusted } \\
\text { mean }\end{array}$ \\
\hline Experiment & A & 28 & 23.02 \\
& C & 24 & 28.03 \\
& D & 22 & 32.87 \\
& B & 23 & 42.14 \\
\hline
\end{tabular}

TABLE 5. Log-linear analysis contrasts for treatments.

\begin{tabular}{lcc}
\hline \hline Factors contrasted & Coefficient & P value \\
\hline Control - Small tag & -0.245 & 0.171 \\
Control - Large tag & -0.302 & 0.001 \\
Small tag - Large tag & -0.057 & 0.653 \\
\hline
\end{tabular}

\section{Discussion}

The influence of treatment on mortality was minor compared to length and experiment influences. Mortality was significantly higher in the large tag groups than the controls, thus indicating that the presence of a tag of this size was a factor in mortality. Mortality was not significantly different between the controls and the small tag groups, and there was no significant difference in mortality between fish with the small and large tags. Thus the size difference of these two tags was not a statistically significant mortality factor. But the consistency in observations of increasing mortality from 
small to large tags in every experiment suggests some effect of increasing tag size.

Hay (1981) found no significant mortality difference between tagged and untagged Pacific herring, but his use of pre-acclimated fish may have affected survivorship; in his study, mortality due to stress or unobserved physical damage related to the conditions of capture in the wild (and therefore inherent in field tagging programs) would have occurred during the acclimation period. Nakashima and Winters (1984) provided an indirect evaluation of herring tagging mortality by estimating the mortality of tagged fish from declines in return rates, and comparing them to mortality rates derived from cohort analysis in the overall untagged population. But they were not comparing immediate post-tagging mortality, since they excluded fish caught within 3 months of release to ensure random distribution throughout the untagged population. They noted higher mortality among tagged versus untagged fish, with larger tags outperforming smaller tags. But they used $20 \mathrm{~mm}$ and $45 \mathrm{~mm}$ tags, whereas we used $40 \mathrm{~mm}$ and $62 \mathrm{~mm}$ tags. Thus, their large tag more closely corresponds to our small tag, making comparisons difficult. Comparison with results in our study is further complicated since they did not estimate the detection rates by fishermen and plant workers who recovered the tags; the enhanced visibility of the larger tags may have outweighed any mortality effects in relation to tag size, although such a bias would cause an underestimate of tag size effect. With respect to field studies that rely on the harvesting and processing components of a fishery for tag returns, the point at which any dual effects of tag size on visibility (detection) and mortality might equalize remains undetermined.

The most significant factor determining mortalities in our study was clearly fish length. Handling alone is likely to cause death in fish smaller than $17 \mathrm{~cm}$ in length, whether they are tagged or not. Parker et al. (1963) noted a distinct difference in mortality between mature and immature coho salmon because of an apparent susceptibility to stress in response to simulated trolling. Since mature fish are generally larger than immature ones, this might also be a length-related effect, similar to our observation on herring.

In this study we tried to duplicate normal field tagging conditions in terms of fish handling and tagging, but any differences in the laboratory conditions may represent less extreme examples of the variability inherent in field tagging programs, conditions which are less likely to be documented. However, even under these conditions, experimental variation in this study was the second most important mortality factor. The fish for experiments $B$ and $C$ came from the same weir on the same day, yet the mortality associated with experiment $B$ was considerably higher than with exper- iment C. Despite apparent commonality in all procedural aspects of collection, some of the experiment $B$ fish began to weaken and die during transfer from the field to the laboratory. It was suspected that they were overcrowded, and 100 fish were removed while still at sea to alleviate stress on the remainder. However, the initial crowding could have been a determining factor in the higher mortality in experiment $\mathrm{B}$. Time required to transport fish from capture sites to the laboratory could also have been a factor, but experiment $D$, which held fish in transit for only $0.5 \mathrm{hr}$, had significantly higher mortalities than experiment $A$ with a transit time of $1.25 \mathrm{hr}$ (see Fig. 1). Thus it appears evident that a number of unexamined factors during the capture and handling could affect subsequent mortality, exclusive of the presence of a tag.

The importance of experimental variation as a mortality factor provides little in the way of cause-effect information, except indicating that fish length, and the presence of a tag, are not solely responsible for low recovery rates of tagged fish. Since the laboratory aspect of the study was controlled and similar in all experiments, this experimental variation reflects the importance of initial field capture and handling procedures on subsequent mortality factors. Von Buddenbrook (1938) and Huntsman (1938) first reported that severe muscular exertion, associated with sustained swimming or struggling on capture, could result in death. Since then a number of studies (Parker and Black, 1959; Parker et al., 1959, 1963) have found a significant correlation between death and high blood lactate levels, an indicator of severe muscle activity. Black (1958) provided a comprehensive review of the affect of high blood lactic acid levels on the physiological well-being of the fish, as well as various other biochemical changes which could cause death due to muscular overexertion. Overall, fish under stress due to overexertion quickly developed high lactic acid levels in muscle tissue or blood, and surviving fish typically returned to pre-exercise levels in 12-16 hr. None of the above studies, however, monitored the surviving fish for longer periods and thus did not address potential long-term mortality as a result of the initial stress. In the context of our study, the existing evidence of lactic acid buildup as a mortality factor may explain the early mortality observed in experiment $B$ during transportation, but does not explain the longer-term mortality. Further research is required on the longer-term physiological status of fish following initial capture and handling to address the mortality observed.

\section{Conclusions}

The difference in tag size used in this study had a minor impact on survivorship for herring $11-23 \mathrm{~cm}$ long. Given the potentially opposing effects of tag size 
on mortality and visibility, it may be a moot point from a field tagging perspective. The presence of a tag on this size range of fish had a statistically discernible impact survivorship, but that impact was not significantly changed by using a smaller tag. The most important consideration by far was fish size. Herring under $17 \mathrm{~cm}$ were more likely to die if handled, irrespective of tagging, whereas larger fish were more likely to survive handling and tagging. The narrow range in lengths between high and low mortality suggests a threshold effect, whereby field selection of only slightly larger fish could significantly enhance returns. It is also evident that improved return rates could result if field capture and handling procedures at tagging were designed to minimize stress and injury. This includes releasing fish as quickly as possible after capture, as earlier suggested by Parker et al. (1959), to reduce lactic acid accumulation.

\section{Acknowledgements}

We are grateful to I. McQuinn and R. L. Stephenson and two anonymous reviewers for their constructive comments on earlier drafts of the manuscript. We also thank Paul Fanning for his suggestions on improving the statistical methodology used in the analysis.

\section{References}

BLACK, E. C. 1958. Hyperactivity as a lethal factor in fish. J. Fish. Res. Board Can., 15: 573-586.

BUDDENBROCK, W. von. 1938. Beobachtungen ueber das Sterben gefangener Seefische und ueber den Milchsaueregehalt der Fischblutes. ICES Rapp. Proc.-Verb., 101: 3-7.

HAY, D. E. 1981. Retention of tags and survival of tagged Pacific herring held in captivity. Can. Tech. Rep. Fish. Aquat. Sci., 1050: 15 p.

HUNTSMAN, A. G. 1938. Overexertion as cause of death of captured fish. Science, 87: 577-578.

JENSEN, A. C. 1963. Further field experiments with tags for haddock. ICNAF Spec. Publ., 4: 194-203.

JONSSON, N., and J. SCABELL. MS 1984. Mortality of tagged and untagged herrings in net cages. ICES C.M. Doc. No. $\mathrm{J}: 34,7 \mathrm{p}$.

KOHLER, A. C. 1964. Movements of halibut on the Nova Scotian and Grand Banks. J. Fish. Res. Board Can., 21: 837-840.

MCCRACKEN, F. D. 1957. Results of cod tagging off eastern Nova Scotia. Fish. Res. Board Can. Atlant. Progr. Rep., 64: 10-15.

MCKENZIE, R. A., and B. E. SKUD. 1958. Herring migrations in the Passamaquoddy region. J. Fish. Res. Board Can., 15: 1329-1343.

MCKENZIE, R. A., and S. N. TIBBO. 1961. Herring movements in the Bay of Fundy and Gulf of Maine, 1957 and 1958. J. Fish. Res. Board Can., 18: 221-252.

NAKASHIMA, B. S., and G. H. WINTERS. 1984. Selection of external tags for marking Atlantic herring (Clupea harengus harengus). Can. J. Fish. Aquat. Sci. ., 41: 1341-1348.

OTT, L. 1988. An introduction to statistical methods and data analysis, 3rd ed. (p. 420-421). PWS-Kent.

PARKER, R. R., and E. C. BLACK. 1959. Muscular fatique and mortality in troll-caught chinook salmon (Oncorhynchus tshawytscha). J. Fish. Res. Board Can., 16: 93-106.

PARKER, R. R., E. C. BLACK, and P. A. LARKIN. 1959. Fatigue and mortality in troll-caught Pacific salmon (Oncorhynchus). J. Fish. Res. Board Can., 16: 429-448.

1963. Some aspects of fish-marking mortality. ICNAF Spec. Publ., 4: 117-122.

PARRISH, B. B., and G. McPHERSON. 1963. Notes on external tagging methods in European herring research. ICNAF Spec. Publ., 4: 336-341.

STOBO, W. T. MS 1976. Some techniques and procedures used to tag herring in ICNAF Subarea 4. ICNAF Res. Doc., No. 101, Serial No. 3924, 12 p.

MS 1983. Report of the ad hoc working group on herring tagging. NAFO SCS Doc., No. 18, Serial No. N723, $41 \mathrm{p}$.

WINTERS, G. H., and J. S. BECKETT. 1978. Migrations, biomass and stock interrelationships of southwest Newfoundland-southern Gulf herring from mark-recapture experiments. ICNAF Res. Bull., 13: 67-79. 
